\title{
Kırşehir ilinin örtü altı domates yetiştiriciliğinde bitkisel artık kaynaklı enerji potansiyelinin mekânsal olarak değerlendirilmesi
}

Spatial evaluation of plant residual energy potential in greenhouse tomato cultivation in Kırşehir

\author{
Sedat BOYACI ${ }^{1 \mathscr{O}}$ (D) Ömer ERTUĞRUL ${ }^{1}$ (D), Gülden ÖZGÜNALTAY ERTUĞRUL ${ }^{1}$ \\ ${ }^{1}$ Kırşehir Ahi Evran Üniversitesi, Ziraat Fakültesi, Biyosistem Mühendisliği Bölümü, Merkez, Kırşehir.
}

\section{MAKALE BILGISI / ARTICLE INFO}

\section{Makale tarihçesi / Article history:}

DOI: $10.37908 /$ mkutbd.933607

Geliş tarihi /Received:06.05.2021

Kabul tarihi/Accepted:03.08.2021

\section{Keywords:}

Greenhouse residues, biomass, evaluation of residues, alternative energy sources, renewable energy sources.

\footnotetext{
Corresponding author: Sedat BOYAC

$\triangle$ :sedat.boyaci@ahievran.edu.tr
}

\section{Ö ZET / A B S T R A C T}

Atıf / Citation: Boyacı S, Ertuğrul Ö, Özgünaltay Ertuğrul G (2021) Kırşehir ilinin örtü altı domates yetiştiriciliğinde bitkisel artık kaynaklı enerji potansiyelinin mekânsal olarak değerlendirilmesi. MKU. Tar. Bil. Derg. 26(3) : 600-609. DOI: 10.37908/mkutbd.933607

\begin{abstract}
Aims: In this study, it is aimed to determine the amount of biomass waste, energy potential and usability of greenhouse tomato production in Kırşehir and to evaluate spatial distribution of the findings.

Methods and Results: In the districts of the Kırşehir, the annual dry waste amounts from tomato plants were calculated as $144525 \mathrm{~kg}, 96350 \mathrm{~kg}$, $22550 \mathrm{~kg}$ and $263425 \mathrm{~kg}$ in total, respectively, in Central, Çiçekdağı and Kaman towns. The thermal energy potential that is obtained in these areas depending on the amount of wastes was calculated as $4046208 \mathrm{MJ}$ in total. Considering the distribution of this value by districts, it was calculated as $2219904 \mathrm{MJ}$ in the Central, $1479936 \mathrm{MJ}$ in Çiçekdağı and $346368 \mathrm{MJ}$ in the Kaman. The production area, production amount, waste and the energy potential values that can be obtained from the wastes were become an updateable database using Geomedia Professional 6.0 geographic information system software which allows spatial queries than maps were produced and evaluated. The corresponding amounts of other sources to the energy potential that can be obtained from tomato wastes is 468311.5 $\mathrm{kg}$ for wood, $301771.4 \mathrm{~kg}$ for domestic lignite coal, $212426.3 \mathrm{~kg}$ for imported Siberian coal, $127028.4 \mathrm{~kg}$ for fuel oil, $126021.5 \mathrm{~m}^{3}$ for natural gas and $1136437.0 \mathrm{kWh}$ for electricity. Considering the $\mathrm{CO}_{2}$ emissions emitted by the other fuels that can be used in equal potential energy value of the biomass wastes that can be obtained from the tomato plant grown under cover in Kırşehir, with coal and natural gas, the possible annual $\mathrm{CO}_{2}$ emission to the atmosphere is $337184.3 \mathrm{~kg}$ and $213550.0 \mathrm{~kg}$ respectively and this amount can be decreased to $28098.7 \mathrm{~kg}$ with the use of the biomass.

Conclusions: Considering the results of the study, it was determined that tomato wastes constitute an important energy potential and are also very important in terms of reducing $\mathrm{CO}_{2}$ emitted into the atmosphere compared to many fossil fuels.

Significance and Impact of the Study: The results show that it is important to utilize the thermal energy potential of tomato wastes to reduce dependency of energy import. Utilization of bioenergy potential of undercover tomato wastes is also important when considering aspects such as reducing the environmental impact of these wastes, providing an alternative to fossil fuels and reducing the $\mathrm{CO}_{2}$ emissions.
\end{abstract}




\section{Giriş}

Biyokütle artıkları, enerji üretimine katkılarının yanı sıra, tarımsal artıklardan yararlanmak çiftlikleri ekonomik olarak iyileştirebilir ki bu da sürdürülebilir tarımın en önemli yönlerinden biridir (Evcim ve ark., 2012). Seralarda yetiştiriciliği yapılan domates, biber ve patlıcan bitkisinin biyokütle artıkları yüksek ısıl değere ve düşük kül içeriğine sahip olmalarından dolayı biyokütle enerji kaynağı olarak büyük bir potansiyel oluşturmaktadır. Ancak bu tür biyokütle artıkları sera çevresine, deniz kenarlarına, dere yataklarına ya da çöp alanlarına atılmakta veya bir parçalayıcı ile parçalandıktan sonra sera toprağına karıştırılmaktadır. Artıkların bu alanlarda doğal olarak kurumasından sonra yakılması hava, çevre ve görüntü kirliliğine neden olmaktadır. Ayrıca bitkideki ilaç ve kimyasal gübre kalıntıları yağışlarla birlikte yeraltına geçerek su kaynaklarını kirletmektedir. Artıkların, sera toprağına karıştırıması ya da sera çevresine atılması, özellikle son yıllarda domates yetiştiriciliğini tehdit eden domates güvesi ve diğer hastalık yapıcı patojen ve zararlıların bir sonraki yetiştiricilik dönemine kadar ortamda kalmasına neden olmakta ve zararlıların etkileri her yıl artmaktadır (Bilgin ve ark., 2012).

Türkiye'nin farklı illerinde sera artıklarının değerlendirilmesiyle ilgili yapılan çalışmalarda, Atilgan ve ark. (2014), Antalya ilinde bitkisel artıkların \%8.7 oranında kompost için kullanılırken \%91.3 oranında tarlaya bırakma, nehir veya dereye atma ve kendini yok etmesini bekleyerek doğaya zarar verecek şekilde bertaraf edildiğini belirtmişlerdir. Güzey ve Atılgan (2015), Denizli ilinde yapmış oldukları çalışmada işletmelerinin \%12'sinin budama işleminden sonra ortaya çıkan bitkisel artıklarını sera içinde bıraktıkları ve $\% 15^{\prime}$ inin ise seranın dışında tarlaya gelişigüzel bıraktıkları, \%37'sinin yakarak ve \%22'sinin ise çöp kutularına atarak bertaraf ettiklerini belirtmişlerdir. Boyacı ve Kartal (2018) Antalya ili Kumluca ilçesinde sera işletmelerinde budamadan çıkan bitkisel artıkların $\% 95.90$ 'ının ve hasattan sonra ortaya çıkan artıkların ise $\% 88.52$ 'sinin doğaya ve atmosfere zarar verecek şekilde bertaraf ettiğini belirtmişlerdir. Boyaci (2018) Kırşehir ilinde budamadan çıkan bitkisel artıklar ve hasattan sonra geriye kalan bitkisel artıkları seraların \%90'ında yüksek tünel işletmelerinin ise tamamında tarlaya bırakma, yakma, çöpe atma ve yakma+çöpe atma şeklinde bertaraf ederken seraların \%10 unda kompost olarak kullanıldığını belirlemiştir. Dolayısı ile bu olumsuz etkilerin önlenmesi için bu artıkların ülke ekonomisine kazandırılması gerekmektedir. Sera biyokütle artıklarının enerji elde etmede briketlenerek katı yakıt olarak kullanılması, biyogaz eldesinde ve kompost üretiminde değerlendirilmesi mümkündür (Bilgin ve ark., 2012).

Sera artıklarından elde edilebilecek enerji potansiyelinin belirlenebilmesi amacıyla yapılan çalışmalarda, Toklu (2017) biyokütle, günümüzde dünyada en çok kullanılan yenilenebilir enerji kaynağı olup çoğunlukla katı formda ve daha az ölçüde sıvı yakıtlar ve gaz formunda kullanılır. Biyokütlenin enerji üretimi için kullanımı modern zamanlarda az bir oranda artmıştır. Biyokütle, Türkiye kırsalındaki en önemli enerji kaynağıdır. Biyokütle, elektrik üretmek, evleri ısıtmak, araçlara yakıt sağlamak ve endüstriyel tesisler için ısısı sağlamak gibi çeşitli enerji intiyaçlarını karşılamak için kullanılır. Türkiye'nin toplam biyokütle enerji potansiyeli yaklaşık 33 MTEP, kullanılabilir biyokütle potansiyeli miktarı ise yaklaşık 17 MTEP'dir. Kullanılabilir biyoenerji kaynaklarından elektrik üretim potansiyeli 2010 yılında 73 MW tır. Çalışma sonunda, Türkiye'de iklim değişikliğinin azaltılması ve enerji sürdürülebilirliği için önemli biyokütle enerji potansiyeli olduğu belirlenmiştir. Bilgin ve ark., (2012) Türkiye'de üretim yapılan cam ve plastik seralardan her yıl kuru madde olarak domates bitkisi için $203904 \mathrm{t}$, biber bitkisi için $35184 \mathrm{t}$ ve patlıcan bitkisi için 13719 t olmak üzere toplamda 252807 t biyokütle atığı çıktığı belirlenmiştir. Toplam sera biyokütle artıklarının yaklaşık olarak \%85' Akdeniz Bölgesinde, \%14'ü ise Ege Bölgesinde çıkmaktadır. Domates, biber ve patlıcan bitkilerinin üst ısıl değerleri sırası ile 15.36, 17.51 ve $17.38 \mathrm{MJ} \mathrm{kg}^{-1}$, kül içerikleri ise \%7.67, \%3.67 ve \%4.33 olarak bulunmuştur. Sera biyokütle artıklarının toplam enerji değeri yaklaşık olarak 3.99 PJ olarak hesaplanmıştır. Bu artıklar briket veya pelet formunda katı yakacak olarak seraların veya evlerin ısıtılmasında, biyogaz eldesinde ve kompost üretiminde kullanılabilir. Karaca (2017) Antalya'da örtü altında yetiştiriciliği yapılan domates, biber ve patlıcan bitkisinin üretimi sonucunda ortaya çıkan biyokütle artık miktarlarını ve enerji potansiyelinin ilçelere göre haritalanması ve bu potansiyelin enerji üretim amacıyla kullanılabilirliğinin incelenmesi amacıyla yürütmüş olduğu çalışmasında, Antalya'da örtü altında yetiştirilen domates biber ve patlıcan bitkilerinden yıllık kuru bazda 202.53 bin ton biyokütle artığı elde edilmektedir. Bu artıkların toplam ısıl değeri ise 3.19 PJ'dir. Bu artıklardan elektrik enerjisi elde etmek için $23 \mathrm{MW}$ Kurulu güce sahip 13 adet birleşik ISI ve güç (CHP) santrali kurulabileceği hesaplanmıştır. Ayrıca bu artıkların tamamının kullanılmasıyla da $\mathrm{CO}_{2}$ emisyonunda \% 92'lik bir azalma sağlanabileceğini bildirmiştir. (Callejón-Ferre ve ark., 2011) İspanya'nın Almeria ilinde seralarda yetiştirilen domates, biber, patlıcan, kabak, fasulye, kavun ve karpuz bitkilerinin yıllık toplam kuru artık miktarının 250126.8 ton ve $3.6 \mathrm{PJ} \mathrm{yıl}^{-1}$ 



belirlenmiştir. Yılmaz ve ark. (2017) kök, gövde, yaprak ve meyve içeren domates ve biber bitkisi hasat artıklarının sığır gübresi ile birlikte anaerobik parçalanmasında en yüksek biyogaz veriminin elde edileceği en uygun organik yükleme ve artık karışım oranlarının saptanması amacıyla yürütmüş oldukları çalışmalarında, $\% 5$ ve $\% 10$ olmak üzere 2 farklı organik yükleme miktarında gerçekleştirilmiştir. Sığır gübresi içerisine domates ve biber hasat artıkları ayrı ayrı olmak üzere $\% 15, \% 30, \% 45, \% 60, \% 75$ ve $\% 90$ oranlarında karıştırılmıştır. Çalışma sonucunda en yüksek biyogaz verimi \%5 organik yükleme miktarında $\% 40$ sığır gübresi ile \%60 domates hasat artıkları karışım oranında elde edilmiştir. Artıkların çevreye zarar verilmeden biyokütle enerjisi olarak kullanılması durumunda çevre kirliliğini azaltması yanında enerji kaynağı olarak ülke ekonomisine önemli katkılar sağlayacaktır. Seralarda ortaya çıkan bitki artıklarının kompostlaştırılmasıyla değerlendirilmesi neticesinde topraklara önemli miktarda bitki besin maddesi kazandırılacak, kullanılan kimyasal gübre miktarının azaltılması ve yakılması durumunda ortaya çıkan çevre kirliliğinin önlenmesi sağlanacaktır (Çıtak ve ark., 2006).

Tarımda sürdürülebilirliğin sağlanması için gıda arzı güvenliği sağlanırken, ekonomik verimliliğin artırılması ve çevresel etkilerin azaltılması önemlidir (Evcim ve ark., 2012), bu amaca yönelik girdi-çıktı analizlerinde su ve enerji girdilerinin yanı sıra, karbon emisyonları, gıda ve biyoenerji gibi çıktıların da belirlenmesi, karar verici mekanizmalarının verimliliğini artıracak isabetli gelecek senaryoları üretebilmesinde fayda sağlayabilir (Degirmencioglu ve ark., 2019). Karaca (2015), çalışmasında Türkiye'de farklı bitki türlerinden yıllık olarak elde edilebilecek artık miktarı potansiyelini belirlemiş ve bu potansiyelin daha etkin bir şekilde izlenebilirliğini coğrafi bilgi sistemi yazılımı aracılığı ile ürettiği haritalar ile sağlamış, enerji ithalatçısı konumundaki Ülkemizin yenilenebilir enerji kaynakları potansiyelini değerlendirmesinin önemini vurgulamıştır. Coğrafi bilgi sistemleri ile oluşturulan güncellenebilir veri tabanlarının sağladığı mekânsal sorgulama olanakları, il düzeyinde oluşturulabilecek karar destek sistemlerinin tutarlılı̆ını artırabilir, Özgünaltay Ertuğrul ve ark. (2019) zamana bağlı mekânsal sorgulama yöntemi ile Kırşehir ili mekanizasyon seviyesini değerlendirmiş, il bazında, güncellenebilir, mekanizasyon seviyesinin farklı tarımsal değişkenler ile etkileşimi değerlendirilebilen bir veri tabanı üretmişlerdir.

Bu çalışmada, Kırşehir ilinde örtü altında yetiştiriciliği yapılan domates işletmelerinin artıklarından elde edilebilecek bitkisel artık kaynaklı enerji potansiyelinin belirlenerek mekânsal olarak değerlendirilmesini ve enerji potansiyelinin farklı yakıtlardaki eş değerliğinin ortaya koyulması amaçlanmıştır.

\section{MATERYAL ve YÖNTEM}

Kırşehir ilinin örtü altı biyokütle enerji potansiyelinin belirlenmesinde Türkiye İstatistik Kurumunun 2020 yılı verileri dikkate alınmıştır (Anonim, 2021a). Çalışmada, Kırşehir ilinin çalışma alanı olarak seçilmesinde ilin Türkiye'de ki toplam sera alanı ve üretim miktarı bakımından düşük alan ve üretim alanına sahip olsada sahip olduğu jeotermal kaynaklar nedeniyle ileriki yıllarda örtü altı tarımında önemli bir potansiyel oluşturacağı öngörülmüştür. Buna paralel olarak artan alan ve üretim ile birlikte çok daha fazla örtü altı biyokütle artığının oluşacağı dikkate alınması gerektiği öngörülmüştür. Sera tarımsal artık materyali olarak ise dünyada ve ülkemizde olduğu gibi Kırşehir ilinde de seralarda yetiştiriciliği en çok tercih edilen domates bitkisinin artıkları değerlendirilmeye alınmıştır.

Çalışmada Kırşehir ilinde domates yetiştiriciliği yapılan seralardan elde edilebilecek enerji potansiyelinin belirlenmesinde bir dekarlık alanda belirlenen kuru bazda artık miktarı, yetiştiricilik yapılan alan ve kullanılabilirlik oranı yardımıyla toplam artık miktarları belirlenmiştir (Eşitlik 1). Daha sonra belirlenen artık miktarları ile domates için belirlenen ısıl değer kullanılarak toplam enerji değerleri hesaplanmıştır (Eşitlik 2) (Karaca ve ark., 2016; Karaca, 2017).

$\mathrm{TAM}=\mathrm{KBAM} \cdot \mathrm{YYA} \cdot \mathrm{KO}$

$\mathrm{EP}=\mathrm{TAM} \cdot \mathrm{ID}$

Eşitliklerde; TAM = Toplam atık miktarı (kg), KBAM = Kuru bazda artık miktarı $\left(\mathrm{kg} \mathrm{da}^{-1}\right)$, YYA $=$ Yetiştiricilik yapılan alan (da), $\mathrm{KO}=$ Kullanılabilirlik oranı (\%), $\mathrm{EP}=$ Enerji potansiyeli (MJ), ID = Kuru bazda ısıl değer $\left(\mathrm{MJ} \mathrm{kg}^{-1}\right)$

Domates, bitkisi için birim alan başına ortaya çıkan kuru biyokütle artık miktarının hesaplanmasında Bilgin ve ark. (2012) tarafından belirlenen değer kullanılmıştır. Buna göre plastik serada üretilen domates için kuru bazda artık miktarı $1025 \mathrm{~kg} \mathrm{da}^{-1}$, kuru bazda ısıl değeri ise 15.36

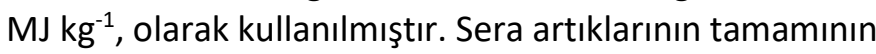
bulunduğu alandan uzaklaştırılabilmesi ve toplanabilmesinden dolayı sera artıklarının kullanılabilirlik oranı \%100 olarak kabul edilmiştir (Karaca ve ark., 2016; Atılgan ve ark., 2020).

Çalışmada elde edilen enerji potansiyeline karşııı gelen enerjinin farklı enerji kaynaklarına dönüşümleri ve maliyetleri Çizelge 1 yardımıyla hesaplanmıştır (Anonim, 2021b). Biyokütlenin atmosfere saldığı $\mathrm{CO}_{2}$ miktarı 0.025 $\mathrm{kg} \mathrm{CO}_{2} \mathrm{kWh}^{-1}$, kömür için $0.3 \mathrm{~kg} \mathrm{CO}_{2} \mathrm{kWh}^{-1}$ ve doğalgaz 
için $0.19 \mathrm{~kg} \mathrm{CO}_{2} \mathrm{kWh}^{-1}$ olarak hesaplanmıştır (Hodsman ve Smallwood, 2005).

Çizelge 1. Farklı yakıtların ısıl değerleri, yanma verimi ve 2021 yılı birim fiyatları Table 1.Thermal values, combustion efficiency and 2021 unit prices of different fuels

\begin{tabular}{llll}
\hline Yakıt cinsi & $\begin{array}{l}\text { Yakıtın alt Isıl değeri } \\
\text { (kWh) }\end{array}$ & $\begin{array}{l}\text { Yanma verimi } \\
\text { (\%) }\end{array}$ & $\begin{array}{l}\text { Birim fiyatı } \\
\text { (TL) }\end{array}$ \\
\hline Odun $(\mathrm{kg})$ & 4.00 & 0.60 & 0.975 \\
Yerli linyit kömürü $(\mathrm{kg})$ & 5.73 & 0.65 & 0.805 \\
Itthal sibirya kömürü $(\mathrm{kg})$ & 8.14 & 0.65 & 1.347 \\
Fuel-oil No: $6(\mathrm{~kg})$ & 11.06 & 0.80 & 3.610 \\
Doğalgaz $\left(\mathrm{m}^{3}\right)$ & 9.59 & 0.93 & 1.712 \\
Elektrik $(\mathrm{kWh})$ & 0.999 & 0.99 & 0.785 \\
\hline
\end{tabular}

Coğrafi bilgi sistemi yazılımları daha önce farklı çalışmalarda mekânsal sorgulamaları ve buna bağıı haritalamaları yapabilmek amaçlı kullanıımıştır (Karaca, 2015; Özgünaltay Ertuğrul ve ark., 2019; Özgünaltay Ertuğrul ve Değirmencioğlu, 2021). Bu çalışmada mekânsal sorgulama becerisine sahip veri tabanı oluşturulmasında Geomedia Professional 6.0 yazııımı kullanılarak, Kırşehir ilinin ilçelerine göre domates bitkisinin üretim alanı, üretim miktarı, artık potansiyeli ve enerji potansiyeli dağılımları haritalandırılarak yorumlanmıştır.

\section{BULGULAR ve TARTIŞMA}

Kırşehir ilinde, ilçe bazında domates yetiştiriciliği yapılan alanlar Şekil 1'de verilmiştir. Kırşehir ilinde toplam 305 dekar örtüaltı alanının 257 dekarında domates yetiştiriciliği yapılmaktadır. Kırşehir ilinde 7 ilçenin 3'ünde yapılan domates yetiştiriciliği, ilin toplam örtü alanının \%84.3'ünü teşkil etmektedir.

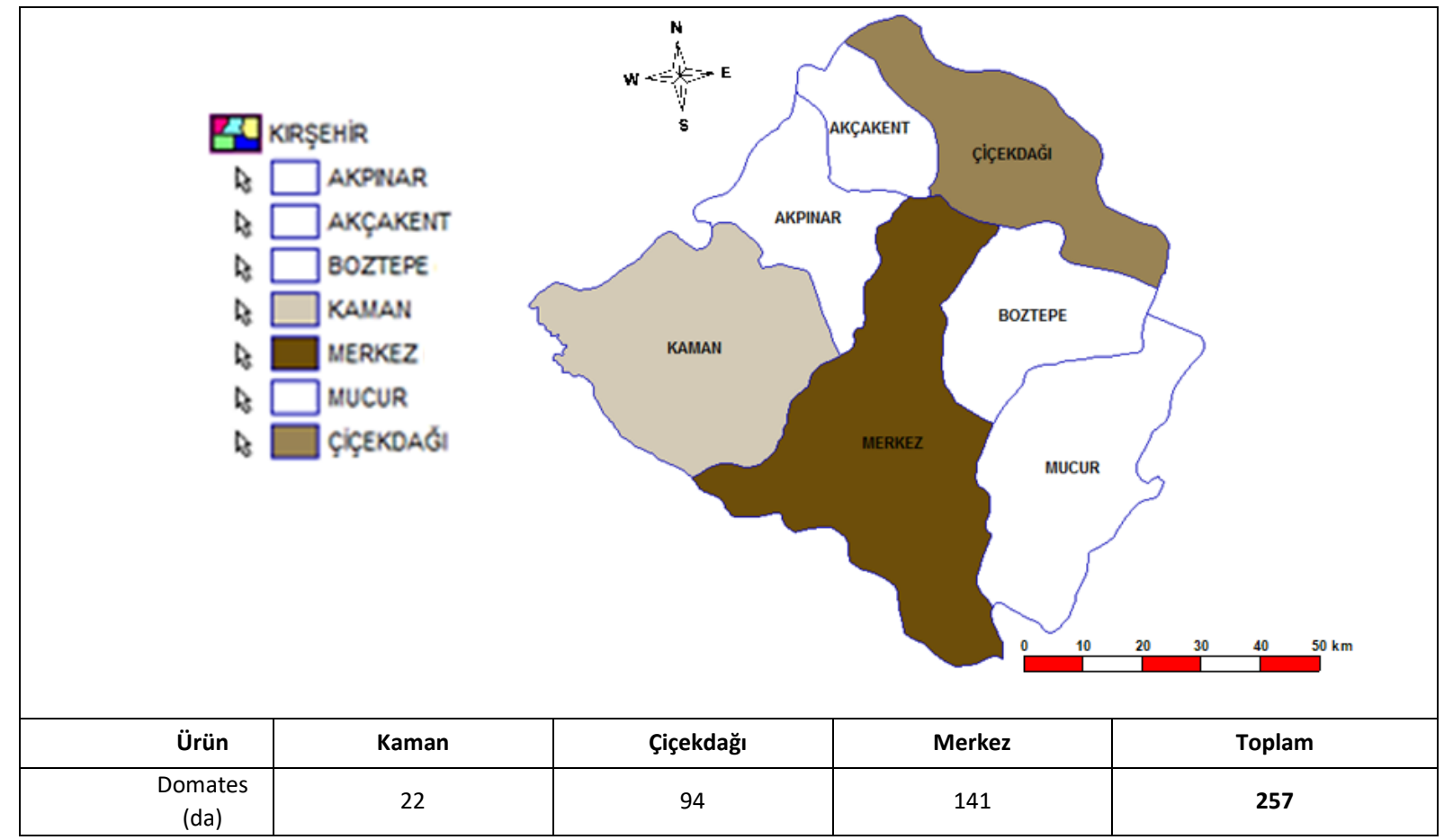

Şekil 1. Kırşehir ilinde, ilçelere göre, örtü altı domates yetiştiriciliği yapılan alanların mekânsal gösterimi.

Figure 1. Spatial representation of greenhouse tomato growing areas in Kırşehir province according to districts.

İlçelere göre örtü altı domates yetiştiriciliği yapılan alanlara bakıldığında yedi ilçesi bulunan Kırşehir ilinin 3 ilçesinde yetiştiricilik yapıldığı görülmektedir. İlin Merkez ilçesinde ve Çiçekdağı ilçelerinde bulunan topraksız tarım 
seralarında jeotermal kaynak ile ısıtması yapılırken Kaman ilçesinde yetiştiricilik ekolojiye bağlı olarak yapılmakta ve ısıtma don tehlikesinden korunma amaçlı olarak fosil yakıtlar ile yapılmaktadır.

Kırşehir ilinde domates üretim miktarları Şekil 2 de verilmiştir. Kırşehir ilinde 2020 yılında toplam 8696 ton örtüaltı üretim gerçekleşmiş olup, bunun 8647 tonu domatestir. Domates seralarda yetiştiriciliği yapılan ürünler arasında en yaygın olan üründür (Alkoaik ve Ghaly 2006; Hochmuth, 2012). Kırşehir ilinde de domates üretimi toplam üretimin \%99.44'ü ile en yaygın ve en çok üretimi yapılan ürün olduğu belirlenmiştir.

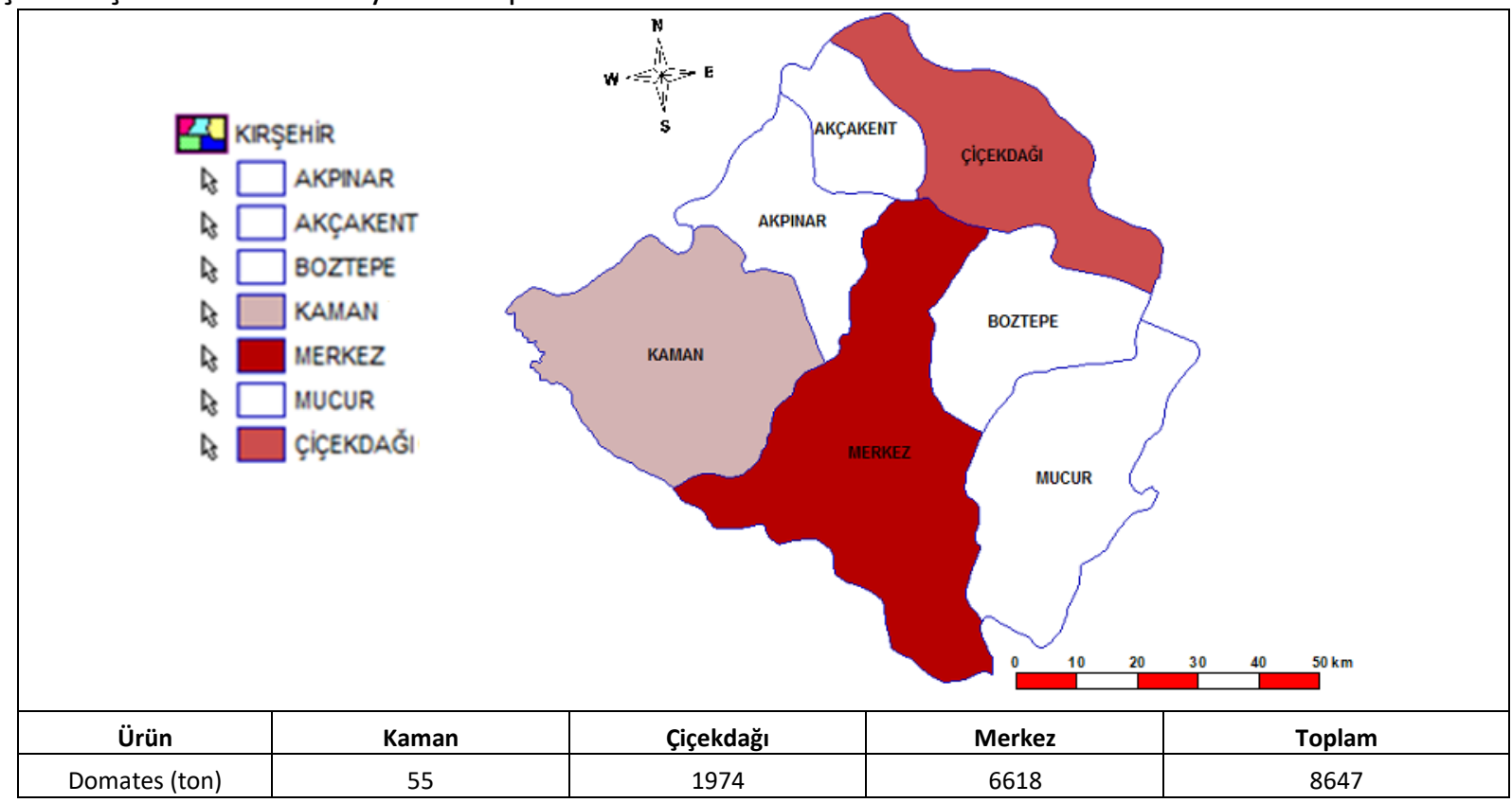

Şekil 2. Kırşehir ilinde, ilçelere göre, örtü altı domates üretim miktarlarının mekânsal gösterimi.

Figure 2. Spatial representation of greenhouse tomato production amounts by districts in the province of Kırşehir.

Şekil 2'de görüldüğü üzere Kırşehir ilinde örtü altı domates üretiminin en fazla yapıldığı ilçenin Merkez ilçe olduğu belirlenmiştir. Merkez ilçeden sonra sırasıyla Çiçekdağı ve Kaman ilçelerinde örtü altı domates üretimi yapıldığı görülmüştür. Merkez ilçede yapılan yetiştiricilikte dekara ortalama 47 ton ürün alınırken, Çiçekdağı ilçesinde 21 ton ve Kaman ilçesinde 2.5 ton ürün alındığı belirlenmiştir. Merkez ve Çiçekdağı ilçesinde jeotermal ile ısıtması yapılan ve iklimlendirilen modern seralarda yıl boyu yetiştiricilik yapılabilmesi nedeniyle, ekolojiye bağlı yetiştiricilik yapılan, don tehlikesinden korunma amaçlı ısıtılan ve iklimlendirmenin yetersiz kaldığı Kaman ilçesindeki yetiştiricilik yöntemlerine göre domates üretim miktarının belirgin oranda yükseldiği görülmüştür.

Üretim verileri kullanılarak hesaplanan domates bitkisinin Kırşehir ilinin ilçeleri için haritalanan artık miktarları ve bunların enerji potansiyelinin dağılımını ilçeler bazında Şekil 3'te görülmektedir. 


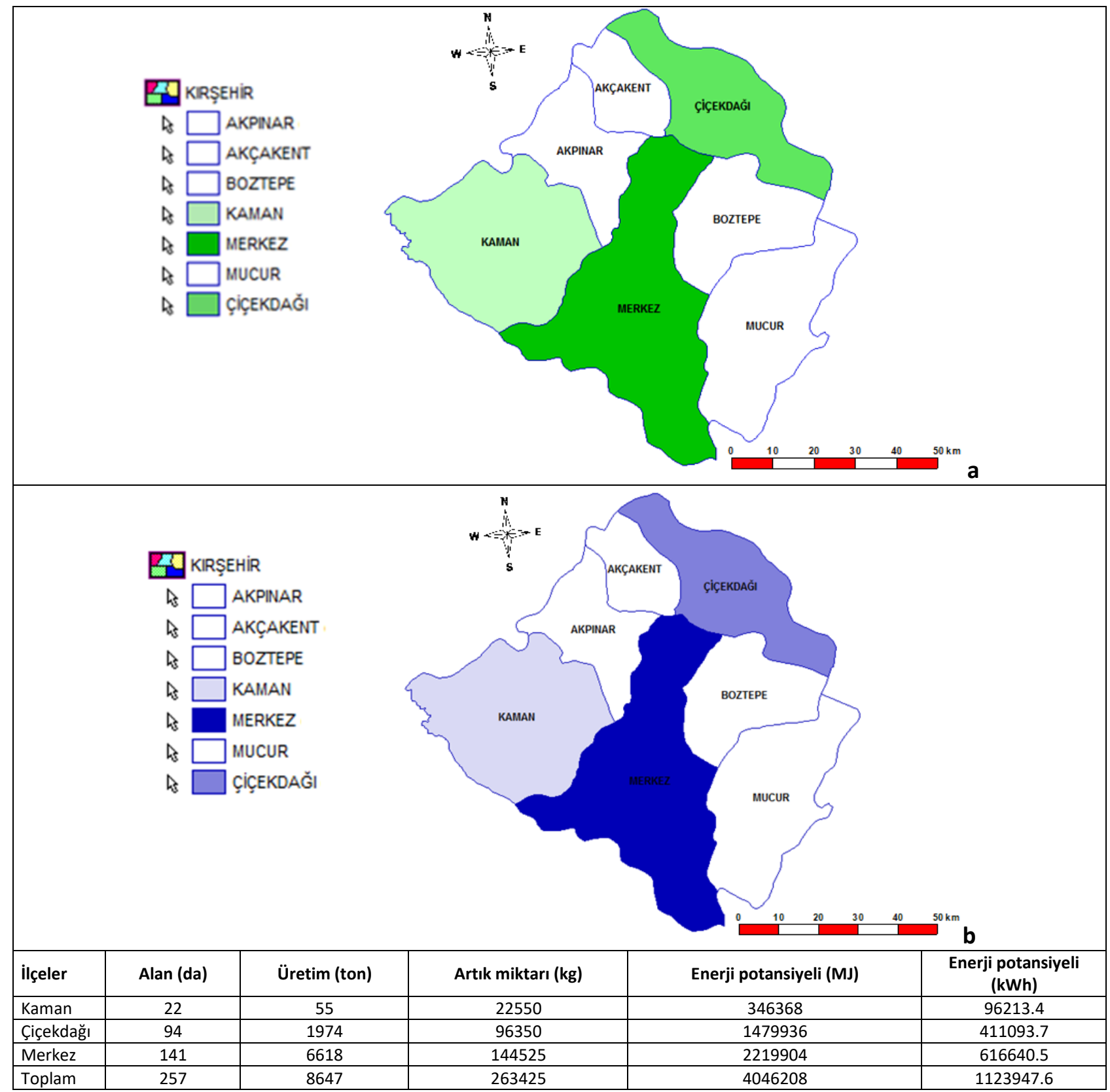

Şekil 3. Kırşehir ilinde, ilçelere göre, örtü altı domates üretiminde elde edilebilecek artık potansiyeli (a) ve enerji potansiyelinin (b) mekânsal gösterimi.

Figure3. Spatial representation of residue potential (a) and energy potential (b) that can be obtained in greenhouse tomato production in Kırşehir province according to the districts.

Kırşehir ilinde domates üretiminin alan ve üretim bakımından en fazla olduğu ilçenin Merkez ilçe olduğu ve buna bağı olarak en fazla artık miktarı ve buna bağlı enerji potansiyelinin Merkez ilçede oluştuğu belirlenmiştir. İlçelerde elde edilebilecek artık miktarının en yüksek oranını \%54.86'ünün Merkez ilçesinde olduğu bunu \%36.58 ile Çiçekdağı ve \%8.56 ile Kaman ilçesinde olduğu belirlenmiştir. Kırşehir ilinde örtü altı domates üretiminden elde edilebilecek toplam artık miktarına bağlı olarak elde edilebilecek enerji potansiyeli toplamda 4046208.06 MJ (1123947.6kWh) olarak hesaplanmıştır.
$\mathrm{Bu}$ değerin ilçelere göre dağılımına bakıldığında ise Merkez ilçede 2219904 MJ (616640.5 kWh), Çiçekdağı ilçesinde 1479936 MJ (411093.7 kWh) ve Kaman ilçesinde 346368 MJ $(96213.4 \mathrm{kWh})$ olarak hesaplanmıştır.

Domates artıklarından elde edilebilecek artık ve enerji potansiyeli ile ilgili yapılan çalışmalarda, Karaca, (2017) tarafından Antalya ilinde yapmış olduğu çalışmasında toplam 159170 dekar alanda 2109938 ton domates üretimi yapıldığı, bu üretimden kaynaklanan artık miktarının 165294 ton olduğu ve bu artık miktarına 
karşılık gelen enerji değerinin 2538915 GJ olduğunu bildirmiştir. Atılgan ve ark., (2020) tarafından Antalya ilinde yapılan çalışmada, toplam 176599 dekar alanda 2421247 ton domates üretimi yapıldığı, bu üretimden kaynaklanan artık miktarının 241982.96 kg olduğu ve bu artık miktarına karşılık gelen enerji değerinin 3716858.26 MJ olduğunu bildirmiştir. İspanya'nın Almeria ilinde 10250 ha lık sera alanında yetiştirilen domates bitkisinden 100450 ton kuru kütle elde edildiğini bunun

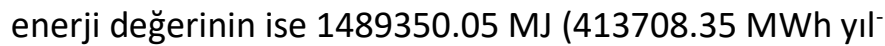
$\left.{ }^{1}\right)$ lük enerjiye karşılık geldiği belirlenmiştir (CallejónFerre ve ark., 2011). Karaca ve ark. (2016) Aydın ilinde seracılığın çoğunlukta olduğu Sultanhisar, Nazilli ve Söke ilçelerinde yer alan sera artıkları miktarı 686 ton olup, enerji potansiyeli $10938 \mathrm{GJ}$ değerine karşılık gelmektedir. Çalışma sonuçları araştırmacıların yapmış oldukları çalışmalar ile değerlendirildiğinde sera artıklarının benzer olarak önemli miktarda enerji potansiyelinin olduğu ve bu enerjinin enerjide dışa bağlı olan ülkemiz için son derece önemli olduğu belirlenmiştir.

Biyokütle, kaynak çeşitliliği açısından diğer alternatif enerji kaynaklarından farklılık gösterir ve birçok dönüştürme işlemiyle enerjiye dönüştürülebilir (Toklu, 2017). Domates artıklarından elde edilebilecek enerji potansiyelinin farklı yakıtlardaki eş değer karşılıkları Çizelge 2'de, TL karşılıkları Çizelge 3'te verilmiştir.

Çizelge 2. Bitkisel artık kaynaklı enerji potansiyelinin farklı enerji kaynaklarına dönüşümleri

Table 2.Transformations of plant residual energy potential into different energy sources

\begin{tabular}{llllllll}
\hline Illçeler & $\begin{array}{l}\text { Enerji } \\
\text { Potansiyeli } \\
(\mathrm{MJ})\end{array}$ & Odun $(\mathrm{kg})$ & $\begin{array}{l}\text { Yerli linyit } \\
\text { Kömürü } \\
(\mathrm{kg})\end{array}$ & $\begin{array}{l}\text { Ithal Sibirya } \\
\text { Kömürü } \\
(\mathrm{kg})\end{array}$ & $\begin{array}{l}\text { Fueloil } \\
(\mathrm{kg})\end{array}$ & $\begin{array}{l}\text { Doğalgaz } \\
\left(\mathrm{m}^{3}\right)\end{array}$ & $\begin{array}{l}\text { Elektrik } \\
(\mathrm{kWh})\end{array}$ \\
\hline Kaman & 346368 & 40088.9 & 25832.6 & 18184.4 & 10874.0 & 10787.8 & 97282.5 \\
Çiçekdağı & 1479936 & 171289.0 & 110375.5 & 77696.8 & 46461.8 & 46093.5 & 415661.8 \\
Merkez & 2219904 & 256933.5 & 165563.3 & 116545.2 & 69692.6 & 69140.2 & 623492.7 \\
\hline Toplam & 4046208 & 468311.5 & 301771.4 & 212426.3 & 127028.4 & 126021.5 & 1136437.0 \\
\hline
\end{tabular}

Çizelge 3. Farklı enerji kaynaklarının TL karşılıkları

Table 3.Turkish Liras equivalents of different energy sources

\begin{tabular}{lllllll}
\hline Illçeler & $\begin{array}{l}\text { Odun } \\
(\mathrm{TL})\end{array}$ & $\begin{array}{l}\text { Yerli linyit } \\
\text { Kömürü } \\
(\mathrm{TL})\end{array}$ & $\begin{array}{l}\text { ithal Sibirya } \\
\text { Kömürü } \\
(\mathrm{TL})\end{array}$ & $\begin{array}{l}\text { Fuel-oil } \\
(\mathrm{TL})\end{array}$ & $\begin{array}{l}\text { Doğalgaz } \\
(\mathrm{TL})\end{array}$ & $\begin{array}{l}\text { Elektrik } \\
(\mathrm{TL})\end{array}$ \\
\hline Kaman & 96213.4 & 39086.7 & 20795.2 & 24502.5 & 39257.1 & 18469.3 \\
Çiçekdağı & 411093.7 & 167006.8 & 88852.3 & 104692.5 & 167734.8 & 78914.3 \\
Merkez & 616640.5 & 250510.2 & 133278.5 & 157038.8 & 251602.2 & 118371.4 \\
\hline Toplam & 1123947.6 & 456603.7 & 242926.0 & 286233.8 & 458594.2 & 215755.0 \\
\hline
\end{tabular}

Yapılan hesaplamalar sonucunda domates artıklarından elde edilebilecek enerji potansiyeline karşılık gelen odun miktarı toplamda $468311.5 \mathrm{~kg}$, yerli linyit kömürü $301771.4 \mathrm{~kg}$, ithal Sibirya kömürü $212426.3 \mathrm{~kg}$, fueloil $127028.4 \mathrm{~kg}$, doğalgaz $126021.5 \mathrm{~m}^{3}$ ve elektrik 1136437.0 kWh'lik enerjiye karşılık gelmektedir. Yakıtların TL karşılıklarına bakılınca odun tutarı $1123947.6 \mathrm{TL}$, yerli linyit kömürü $456603.7 \mathrm{TL}$, ithal Sibirya kömürü $242926.0 \mathrm{TL}$, fuel-oil $286233.8 \mathrm{TL}$, doğalgaz 458594.2 TL ve elektrik 215755.0 TL ye denk geldiği hesaplanmıştır. Elde edilen sonuçlara bakıldığında, domates artıklarında elde edilebilecek enerji potansiyelinin farklı yakıtlara dönüşümleri ile yaygın olarak kullanılan fosil yakıtlardan önemli miktarda maddi tasarruf edilebileceği belirlenmiştir.

Bunun yanında yakıtların atmosfere saldığı $\mathrm{CO}_{2}$ emisyonlarına bakılacak olursa Kırşehir ilinde örtü altında yetiştirilen domates bitkisinden elde edilecek olan biyokütle artıklarının toplam enerji değerinin (4046208 MJ) tamamının kömür veya doğalgaz ile ikame edilmesiyle, yıllık atmosfere saldığı $\mathrm{CO}_{2}$ emisyonu sırasıyla $337184.3 \mathrm{~kg}, 213550.0 \mathrm{~kg}$ iken, artıkların kullanılmasıyla bu miktar 28098.7 kg'a düşmektedir. Karaca (2017), Antalya ilinde örtü altında yetiştiriciliği yapılan domates, biber ve patlıcan bitkilerinden elde edilecek olan biyokütle artıklarının toplam enerji değerinin (3.19 PJ) tamamının kömür ile ikame edilmesiyle, kömürün yıllık atmosfere saldığı $\mathrm{CO}_{2}$ emisyonu 265.8 Mt iken, artıkların kullanılmasıyla 22.15 Mt'a düştüğünü bildirmiştir. Yapılan hesaplamalar sonucunda biyokütlenin enerji eldesi yanında atmosfere saldığı $\mathrm{CO}_{2}$ miktarınında birçok fosil yakıta göre daha 
düşük olması atmosfere salınan $\mathrm{CO}_{2}$ miktarının azaltılması bakımından da son derece önemlidir.

Dünyada artan insan nüfusu ve gelişen teknolojilere bağlı olarak artan enerji ihtiyacı dikkate alındığında tarımsal artıkların biyoenerji olarak değerlendirilmesi oldukça önem kazanmaktadır. Her yıl Türkiye'de çok büyük miktarlarda organik artık ortaya çıkması, bu artıkların herhangi bir şekilde değerlendirilmeyip yakılarak ya da çöp alanlarına atılarak bertaraf edilmesi söz konusudur (Guresci, 2020). Bu tür artıkların değerlendirilip, ülke ekonomisine kazandırılmasının öncelikli konulardan olması gerektiği düşünülmektedir. Biyokütlenin ülkemizde verimli bir şekilde değerlendirilmesi, artıkların değerlendirilmesi ve yeni iş alanlarının açılmasını sağlayacak bir konudur. Ayrıca, biyokütle içerisinde fosil yakıtlar kadar kanserojen madde ve kükürt olmadığı için olumsuz çevresel etkileri son derece düşük olduğundan çevre kirliliği bakımından olumsuz etkileri daha düşük düzeydedir (Karaca ve ark., 2016). Kırşehir ilinin ilçeleri bazında yapılan çalışmada olumsuz çevresel etkileri oldukça fazla olan bu artıkların enerji amaçlı kullanılması yanında çevresel etkilerinin azaltılması, bölgesel ve ülkesel ekonomiye kazandırılabileceği yapılan hesaplamalar ile belirlenmiştir.

Sonuç olarak, günümüzde artan gıda tüketime bağlı olarak artan tarımsal ürünler oldukça büyük miktarda artık oluşturmaktadır. Bu artıklar çevresel kirletici olarak karşımıza çıksa da bunlardan elde edilecek enerji potansiyeli azımsanmayacak kadar büyük olabilmektedir. Çalışma ile elde edilen sonuçlara bakıldığında domates artıklarının önemli bir enerji potansiyel oluşturması yanında birçok fosil yakıtın atmosfere saldığı $\mathrm{CO}_{2}$ in azaltılması bakımından son derece önemli olduğu düşünülmektedir.

Bu çalışmada, Kırşehir ilinin sosyo-ekonomik yapısına önemli ölçüde katkısı olduğu düşünülen örtüaltı domates üretiminde ortaya çıkabilecek bitki artığı potansiyeli ve buna bağlı enerji potansiyelinin belirlenmesi ve mekânsal veri tabanı oluşturularak, bu konuda izlenebilirlik sağlanabilmesi amaçlanmıştır. Buna göre;

- Toplam 257 da alanda, 8647 ton örtü altı domates üretimi yapılmaktadır. Bu üretimin yarıdan fazlası $141 \mathrm{da}$ alan ve 6618 ton üretim ile Merkez ilçede yoğunlaşmıştır.

- Kırşehir ili 2020 yılı örtü altı domates üretiminden elde edilebilecek potansiyel artık miktarı toplam 263425 kg olup, Merkez ilçe 144525 kg, Çiçekdağı 96350 kg ve Kaman 22550 kg olarak hesaplanmıştır.

- Artık miktarlarına bağlı olarak, toplam ısıl enerji üretim potansiyeli $4046208 \mathrm{MJ}$ olarak, elektriksel karşılığı ise 1123947.6 kWh (yaklaşık 1124 MW) olarak hesaplanmıştır. Ortaya konan bu potansiyel, Türkiye'de mevcut hidroelektrik santraller dışında, kurulmuş olan her bir yenilenebilir enerji kaynaklı santralin elektrik üretim kapasitesinden yüksektir.

Bu anlamda, yoğun tarımsal üretime sahip olan Kırşehir ilinde sadece örtü altı domates yetiştiriciliği sonucunda elde edilebilecek artıklar değerlendirilebilse bile, elektrik üretim sistemine önemli katkısı olabilecek, modern yenilenebilir enerji santrallerinden birinin bu bölgede kurulabileceği düşünülmektedir. Diğer bitkisel ve hayvansal üretim kaynaklı artıkların da değerlendirilmesi durumunda, hammadde tedarikinin sürekliliğinin sağlanmasının yanında, biyokütle kaynaklı enerji üretim potansiyelinin çok daha yüksek seviyelerde olacağı ön görülebilir.

\section{ÖZET}

Amaç: Bu çalışmada, Kırşehir ilinin örtü altı domates üretimi sonunda oluşan biyokütle artık miktarının ve enerji potansiyelinin ilçelere göre mekânsal olarak değerlendirilmesi ve bu potansiyelin enerji üretimi amacıyla kullanılabilirliğinin belirlenmesi amaçlanmıştır.

Yöntemler ve Bulgular: illin ilçelerinde domates bitkisinden yıllık kuru bazda artık miktarının Merkez, Çiçekdağı ve Kaman ilçesinde sırasıyla 144525 kg, 96350 $\mathrm{kg}$ ve $22550 \mathrm{~kg}$ olmak üzere toplamda $263425 \mathrm{~kg}$ olarak hesaplanmıştır. Bu alanlarda artık miktarlarına bağlı olarak elde edilebilecek ısıl enerji potansiyeli toplamda 4046208 MJ olarak hesaplanmıştır. Bu değerin ilçelere göre dağılımına bakıldığında ise Merkez ilçede 2219904 MJ, Çiçekdağı ilçesinde 1479936 MJ ve Kaman ilçesinde 346368 MJ olarak hesaplanmıştır. Üretim alanı, üretim miktarı, artık ve artıklardan elde edilebilecek enerji potansiyeli değerleri Geomedia Professional 6.0 coğrafi bilgi sistemi yazılımı kullanılarak mekânsal sorgulamalara olanak sağlayan, güncellenebilir bir veri tabanı haline getirilmiş ve haritalar üretilerek değerlendirilmiştir. Yapılan hesaplamalar sonucunda domates artıklarından elde edilebilecek enerji potansiyeline karşılık gelen odun miktarı toplamda $468311.5 \mathrm{~kg}$, yerli linyit kömürü $301771.4 \mathrm{~kg}$, ithal Sibirya kömürü $212426.3 \mathrm{~kg}$, fueloil $127028.4 \mathrm{~kg}$, doğalgaz $126021.5 \mathrm{~m}^{3}$ ve elektrik $1136437.0 \mathrm{kWh}$ 'lik enerjiye karşlık gelmektedir. Bunun yanında yakıtların atmosfere saldığı $\mathrm{CO}_{2}$ emisyonları incelendiğinde, Kırşehir ilinde örtü altında yetiştirilen domates bitkisinden elde edilebilecek biyokütle artıklarının toplam enerji değerinin tamamının kömür veya doğalgaz ile ikame edilmesiyle, yıllık atmosfere saldığı $\mathrm{CO}_{2}$ emisyonu sırasıyla $337184.3 \mathrm{~kg}, 213550.0 \mathrm{~kg}$ iken, artıkların kullanılmasıyla bu miktar 28098.7 kg'a düşebileceği belirlenmiştir.

Genel Yorum: Çalışma ile elde edilen sonuçlara bakıldığında domates artıklarının önemli bir enerji 
potansiyel oluşturması yanında birçok fosil yakıta göre atmosfere salınan $\mathrm{CO}_{2}$ in azaltılması bakımından da son derece önemli olduğu belirlenmiştir.

Çalışmanın Önemi ve Etkisi: Elde edilen sonuçlar, enerjide dışa bağımlı olan ülkemizde domates artıklarının ısı enerjisi olarak kullanılması durumunda bu artıkların çevresel etkilerinin azaltılması, fosil yakıtlara alternatif olması ve karbondioksit emisyonlarının azaltılması gibi yönleri ele alındığında bu artıkların önemli bir enerji potansiyeline sahip olduğunu göstermiştir.

Anahtar Kelimeler: Sera artıkları, biyokütle, artıkların değerlendirilmesi, alternatif enerji kaynakları, yenilenebilir enerji kaynakları.

\section{ÇIKAR ÇATIŞMA BEYANI}

Makale yazarları aralarında herhangi bir çıkar çatışması olmadığını beyan ederler.

\section{ARAŞTIRMACILARIN KATKI ORANI BEYANI}

Yazarlar makaleye eşit oranda katkı sağlamış olduklarını beyan ederler.

\section{KAYNAKLAR}

Alkoaik F, Ghaly AE (2006) Influence of dairy manure addition on the biological and thermal kinetics of composting of greenhouse tomato plant residues. Waste Manage. 26(8): 902-913.

Anonim (2021a) TUiK Bitkisel Üretim İstatistikleri. https://biruni.tuik.gov.tr/medas/?kn=92\&locale $=\operatorname{tr}$ ( Erişim Tarihi: 16 Nisan 2021)

Anonim (2021b) Yakıt fiyatları. http:// www.tesisat.com.tr/yayin/yakit-fiyatlari/ (Erişim Tarihi: 10 Mart 2021)

Atilgan A, Oz H, Yilmaz HI, Uzer H (2014) Determination of current status in the resulting of waste materials from production of greenhouse and its environmental interaction. Engineering for Rural Development 29: 120-125.

Atılgan A, Saltuk B, Ertop H, Aksoy E (2020) Sera atıklarından biyogaz enerji potansiyelinin belirlenerek sayısal haritalarının oluşturulması: Antalya ili örneği. Euroasia Journal of Mathematics, Engineering, Natural \& Medical Sciences 7(12): 19-30.

Bilgin S, Ertekin C, Kürklü A (2012) Türkiye'deki sera bitkisel biyokütle atık miktarının belirlenmesi. 27. Tarımsal Mekanizasyon Ulusal Kongresi, 5-7 Eylül, Samsun, Türkiye. s.499-508.
Boyaci S (2018) Environmental problems caused by agricultural wastes resulting from greenhouse and high tunnel cultivation and solution suggestions. Fresenius Environ. Bull. 27(4): 2510-2517.

Boyacı S, Kartal S (2019) Determination of environmental problems caused by agricultural wastes in greenhouse enterprises and solution suggestions. MKU. Tar. Bil. Derg. 24 (ÖzelSayı): 51-60.

Callejón-Ferre AJ, Velázquez-Martí B, López-Martínez JA, Manzano-Agugliaro F (2011) Greenhouse crop residues: Energy potential and models for the prediction of their higher heating value. Renew. Sustain. Energy Rev. 15: 948-955.

Çıtak S, Sönmez S, Öktüren F (2006) The usage possibility of plant origin wastes in agriculture. Derim 23: 40-53.

Degirmencioglu A, Mohtar RH, Daher BT, Ozgunaltay Ertugrul G, Ertugrul $O$ (2019) Assessing the sustainability of crop production in the Gediz Basin, Turkey: a water, energy, and food nexus approach. Fresenius Environmental Bull. 28(4): 2511-2522.

Evcim HÜ, Değirmencioğlu A, Özgünaltay Ertuğrul G, Aygün I (2012) Advancements and transitions in technologies for sustainable agricultural production. Economic and Environmental Studies 12(4): 459-466.

Guresci E (2020) A general view of the biomass energy potential and its use in Turkey. P I Civil Eng-Energy 173(4): 141-149.

Güzey S, Atılgan A (2015) Sera yetiştiriciliğinde kirletici faktörlerin belirlenmesi: Denizli ili örneği. Süleyman Demirel Üniv. Zir. Fak. Derg. 10(2): 22-33.

Hochmuth GJ (2012) Production of greenhouse tomatoes-Florida greenhouse vegetable production handbook. 3: 1-16.

Hodsman L, Smallwood M (2005) Wood fuel heating in the North of England: A Practical Guide. Retrieved March 10, 2021, from https://madenecofuels.co.uk/wp-content/uploads 2016/02/woodfuel-heating-in-the-north-ofengland.pdf

Karaca C (2017) Antalya' da seracılık biyokütle artıklarının potansiyelinin haritalanması ve enerji üretim amacıyla değerlendirilmesi. Mediterranean Agricultural Sciences 30(1): 21-25.

Karaca C, Öztürk HH, Ekinci K (2016) Aydın ilinde bitkisel kökenli tarımsal biyokütle potansiyeli ve enerji üretimi amacıyla değerlendirilmesi. 2.Ulusal Biyoyakıtlar Sempozyumu, 27-30 Eylül, Samsun, Türkiye. s.47-56.

Karaca C (2015) Mapping of energy potential through annual crop residues in Turkey. Int. J. Agric. \& Biol. Eng. 8(2): 104-109. 
Özgünaltay Ertuğrul G, Ertuğrul Ö, Değirmencioğlu A (2019) Determination of agricultural mechanization levels in Kırşehir province using Geographical Information Systems (GIS). CRAcad Bulg. Sci. 72(8): 1144-1152.

Özgünaltay Ertuğrul G, Değirmencioğlu A (2021) A GISbased approach on annual tractor use, soil type and crop pattern interactions in some provinces of the Aegean region. Turkish Journal of Agriculture-Food Science and Technology 9(8): 1384-1389.
Toklu E (2017) Biomass energy potential and utilization in Turkey. Renewable Energy 107: 235-244.

Yılmaz F, Kökdemir Ünşar E, Akman HE, Perendeci NA, Yaldız O (2017) Büyükbaş hayvan atıkları ile sera hasat atıklarından biyogaz üretimi ve birlikte anaerobic parçalanma prosesinin modellenmesi. YYÜ Tar. Bil. Derg. 28(1): 62-69. 